Article

\title{
An Energy-Based Control Strategy for Battery Energy Storage Systems: A Case Study on Microgrid Applications
}

\author{
Rui Hou ${ }^{1,2}$, Thai-Thanh Nguyen ${ }^{1}$, Hak-Man Kim ${ }^{1, *}$, Huihui Song ${ }^{2}$ and Yanbin Qu ${ }^{2, *}$ \\ 1 Department of Electrical Engineering, Incheon National University, (Songdo-dong) 119 Academy-ro, \\ Yeonsu-gu, Incheon 22012, Korea; ntthanh@inu.ac.kr \\ 2 School of Information and Electrical Engineering, Harbin Institute of Technology at Weihai, \\ No.2 in Wenhua Xi Road, Weihai 264209, China; houruihit@163.com (R.H.); songhh@hitwh.edu.cn (H.S.) \\ * Correspondence: hmkim@inu.ac.kr (H.-M.K.); quyanbin@hit.edu.cn (Y.Q.); \\ Tel.: +82-32-835-8769 (H.-M.K.); +86-189-6317-2108 (Y.Q.); \\ Fax: +82-32-835-0773 (H.-M.K.); +86-631-568-7028 (Y.Q.)
}

Academic Editor: Wenxin Liu

Received: 7 December 2016; Accepted: 7 February 2017; Published: 13 February 2017

\begin{abstract}
Battery energy storage systems (BESSs) with proportional-integral (PI) control methods have been widely studied in microgrids (MGs). However, the performance of PI control methods might be unsatisfactory for BESSs due to the nonlinear characteristics of the system. To overcome this problem, an energy-based (EB) control method is applied to control the converter of a BESS in this study. The EB method is a robust nonlinear control method based on passivity theory with good performance in both transient and steady states. The detailed design process of the EB method in the BESS by adopting an interconnection and damping assignment (IDA) strategy is described. The design process comprises three steps: the construction of the port-controlled Hamiltonian model, the determination of the equilibrium point and the solution of the undetermined matrix. In addition, integral action is combined to eliminate the steady state error generated by the model mismatch. To establish the correctness and validity of the proposed method, we implement several case simulation studies based on a test MG system and compare the control performance of the EB and PI methods carefully. The case simulation results demonstrate that the EB method has better tracking and anti-disturbance performance compared with the classic PI method. Moreover, the proposed EB method shows stronger robustness to the uncertainty of system parameters.
\end{abstract}

Keywords: microgrid (MG); renewable power generation; battery energy storage system (BESS); energy-based (EB) control

\section{Introduction}

The installation of a battery energy storage system (BESS) in a microgrid (MG) provides a variety of MG services such as compensating for fluctuations in renewable power generation sources, voltage support, and frequency regulation [1-5]. The control strategy of the BESS converter plays a major role in the performance of a BESS. Converter control strategies are classified into two types: linear controllers and nonlinear controllers. The conventional linear control strategy is the proportional-integral (PI) method, which is widely researched and applied in real systems, including BESSs [6-8]. Although the PI method is classical and practical, there are still several problems related to the design strategy of PI parameters. Firstly, the PI method is appropriate for a single-input/single-output system, whereas a BESS is a multi-input/multi-output system. Therefore it is difficult to achieve the satisfactory performance by tuning PI parameters [9]. 
If the multi-loop PI strategy is adopted in a BESS, it is rather complicated to design the controller; Secondly, a BESS is a typical nonlinear system. Since the PI method design is usually based on a local linearization model or linear controller with compensation, it can only achieve reliable performance and stability in a certain range for BESS converter control [10]. In order to address the problems of the PI method, advanced nonlinear control methods are recommended for improving BESS converter control performance [11].

In recent years, various nonlinear control methods have been applied to the voltage-source converter (VSC) such as hysteresis control [12], sliding-mode control [13], backstepping design method [14], one-cycle control [15], and fuzzy control [16]. These methods can achieve stronger robustness and a larger stability range compared with PI control. However, their control performance in BESSs may still be unsatisfactory due to their respective drawbacks. For instance, the switching frequency of hysteresis control is not fixed; sliding-mode control has the tremor problem; the major disadvantage of the backstepping method is the explosion of complexity; one-cycle control has a weak ability to resist load disturbances; fuzzy control has poor static characteristics, etc.

Recently the energy-based (EB) method employing the port-controlled Hamiltonian ( $\mathrm{PCH})$ principle has attracted more and more attention [17-19]. This method is a novel nonlinear robust control strategy based on passivity theory. According to this theory, the passive system, characterized by no energy production, will eventually run to the lowest energy point owing to the dissipation. If the system is expected to reach another specified balance position, an appropriate amount of external energy should be injected by the control to supplement the system energy. This process is called energy shaping. Among all the energy shaping implementation methods, interconnection and damping assignment (IDA) is the most effective strategy [20]. Unlike other nonlinear control strategies, the EB method based on IDA strategy employs the structural properties of physical systems to obtain an easily implemented control law [21]. Compared with the conventional PI method, the EB method has superior tracking performance and can achieve stronger stability and robustness in a large region [22]. The complex design process is the main drawback of any EB control strategy. The designer needs some experience to design the EB control, which limits the actual applications of the EB method. However, owing to its advantages in nonlinear and multivariable systems, the EB method has been studied in the field of robot motion control where it has achieved good results. Recently, some researchers have applied the EB method in the power electronics area [22-27]. In [25] the EB method was used in a pulse width modulation (PWM) rectifier. Nonetheless, no comparison between the performance of the PI and EB methods was provided. In [26] the EB method was utilized in a grid-connected converter control application. However, the authors did not consider the influence of model mismatch, neither did they provide a comparison between the PI and EB methods. In [27] the EB method was implemented in an active power filter control application, but robustness to parameter perturbation was not taken into account. Moreover, no design method for PI control was provided, and the performance of the PI method was poor. Up to now, there are almost no papers on the application of the EB method in BESSs. Hence the major contribution of this paper is to employ the EB strategy in a BESS for improving the control performance. Additionally, the step-by-step design strategy of the EB controller is presented, which should be helpful for further studies on EB controllers.

In this study, we consider a test AC MG system with a common structure including a BESS and a wind turbine generator. The BESS can be used for smoothing the wind power fluctuations in the grid-connected mode and regulating frequency in the islanded mode. The BESS consists of a converter system that is used to convert DC power to AC or DC power. Generally, the converter control system of a BESS is based on a PI regulator. In our study, the EB control strategy is used for designing the BESS controller to improve the robustness of the BESS control. The designed EB controller only depends on the converter structure of the BESS such as the DC/DC or DC/AC converters. The MG configuration has no impact on the design of the EB controller. Therefore, our proposed EB control strategy for the BESS can be applied to other MG configurations without any difficulty. In the test MG system, a common single-stage VSC structure is employed for the BESS. It should 
be noted that although the mathematical model of a BESS could be different due to the converter system, the design process of an EB control for other BESS structures is similar. A case study provides a detailed comparison between the performance of EB and PI control. Several cases are considered and tested by the simulation. The robustness of the EB controller against the system uncertainties is analyzed and compared with the PI control. Moreover, a sensibility analysis of the EB control method is presented to evaluate the influence of the system parameters on the control performance. The case simulation results show that stronger tracking, anti-disturbance, and robustness performance are achieved by the EB method compared to the PI method.

This paper is organized into four parts. Firstly, the structure and control scheme of the test MG system are provided in Section 2. Secondly, the detailed step-by-step design method for the EB controller in a BESS, including the consideration of the model errors, is proposed in Section 3. Additionally, the design method of the conventional PI controller used for comparison is briefly presented. Thirdly, Section 4 presents the case simulation study results. By contrast with the PI control, the advantages of the proposed EB method are demonstrated. Finally, the conclusions are summarized in Section 5.

\section{The Test Microgrid System and Battery Energy Storage System Control Scheme}

\subsection{The Structure of the Test Microgrid System}

In this study, we consider a test AC MG system with a common structure including a wind turbine generator, a DG, a BESS and the load. The structure and parameters of the test MG are illustrated in Figure 1. In this study, we utilize a fixed speed wind generator as the main power supply of the MG for the sake of simplicity. The DG serves as the backup power supply. It should be noted that BESS control is relatively independent of the type of renewable productions. Hence the designed BESS controller can naturally apply to any other AC MG configuration with different renewable power generations. The positive direction of each power is defined in Figure 1. $P_{\mathrm{B}}$ can be bidirectional, and we define the charging as the positive direction.

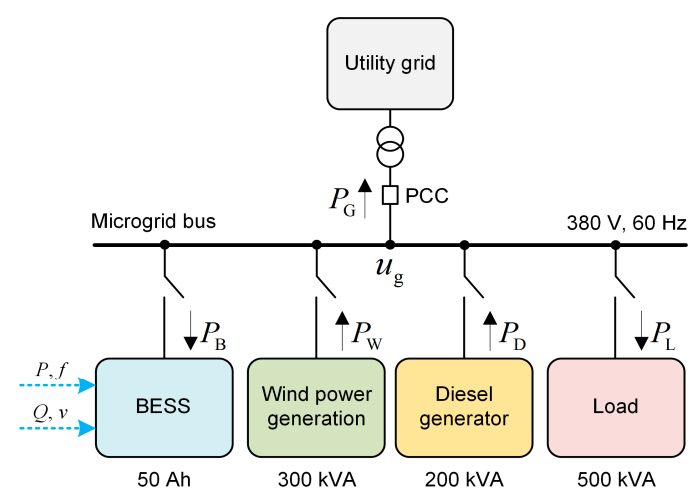

Figure 1. The structure of the test microgrid (MG) system.

\subsection{The Battery Energy Storage System Control Scheme Using Energy-Based Method}

Firstly we assume that the storage capacity of the battery and the energy management system have been properly designed because they are not the concerns of this paper. Hence the state of charge (SOC) of the BESS is ignored in the following parts. The design of the controller depends on the BESS topology which is depicted in Figure 2.

In this study, the generic model of a battery is adopted. Based on [28], this model can precisely represent the general behavior of the battery and is suitable for dynamic simulations. The simple single-stage structure is employed, which means that just one VSC is utilized. Three-phase VSC serves to directly interface the battery with the MG. This BESS topology can apply to AC MGs with 
the common renewable generations such as wind turbine and photovoltaic conditions. In Figure 2, S1-S6 represent the insulated gate bipolar transistors (IGBTs). The connection inductor is used to restrain the high-frequency harmonic. Evidently, when the battery is charged, VSC is in the rectifier mode; on the contrary, when the battery is discharged, VSC is in the inverter mode. It should be emphasized that the DC voltage of VSC is not constant due to the SOC status of the battery. The DC voltage must be high enough to guarantee the proper operation of the VSC.

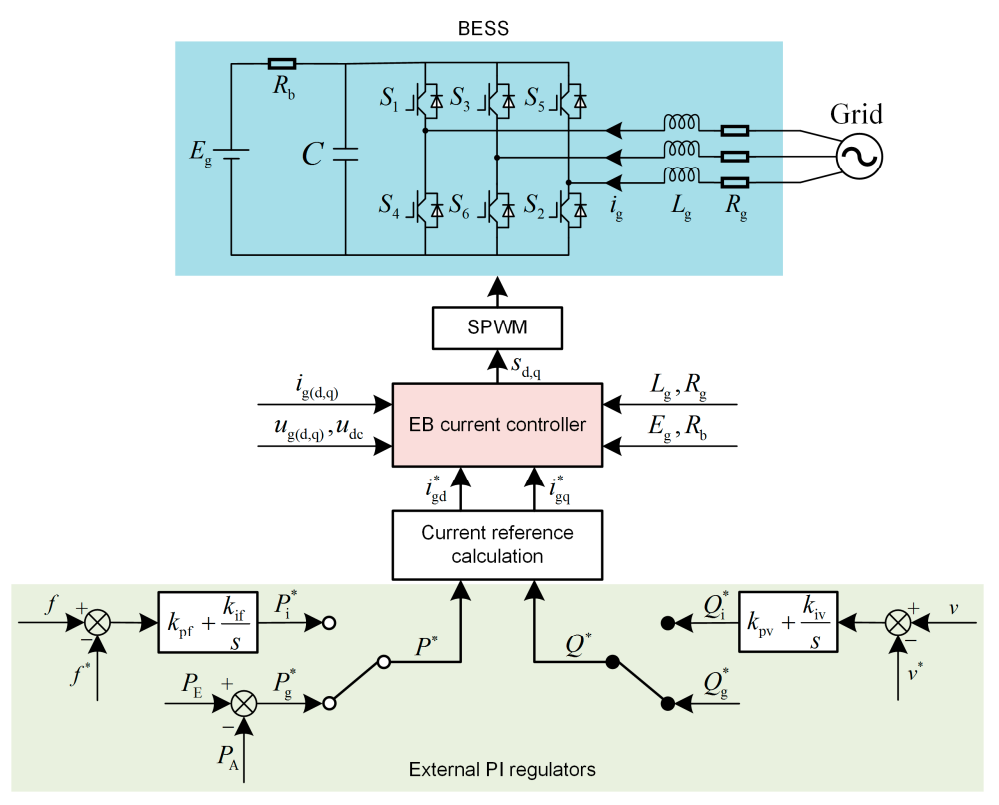

Figure 2. The topology of battery energy storage system (BESS) and energy-based (EB) control scheme.

The BESS control scheme using the EB method is also shown in Figure 2. A d-q frame is employed to simplify the controller. The input of the EB controller is the power reference, and the output is the duty ratio $s$ of the converter. The control object is the BESS current. The EB method can make the BESS power track with the reference by the current closed-loop control. Conventionally, PI control is used in the current loop. In this study, the EB method is implemented to improve the robustness of the system. The reference current is calculated by the reference power directly:

$$
\left\{\begin{array}{l}
i_{\mathrm{gd}}^{*}=\frac{\frac{2}{3}\left(u_{\mathrm{gd}} P^{*}+u_{\mathrm{gq}} Q^{*}\right)}{u_{\mathrm{gd}}^{2}+u_{\mathrm{gq}}^{2}} \\
i_{\mathrm{gq}}^{*}=\frac{\frac{2}{3}\left(u_{\mathrm{gq}} P^{*}-u_{\mathrm{gd}} Q^{*}\right)}{u_{\mathrm{gd}}^{2}+u_{\mathrm{gq}}^{2}}
\end{array}\right.
$$

The additional power feedback outer loop can be employed to increase the control accuracy of power. However, it is difficult to design a dual loop system with an adequate stability margin. In the grid-connected mode, BESS power can be controlled to smooth the output of wind generations. As shown in Figure 2, the real power reference of BESS can be obtained by $P_{\mathrm{g}}^{*}=P_{\mathrm{E}}-P_{\mathrm{A}}$. In the islanded mode, the power references can be obtained by the outer-loop $f-p$ and $v-q$ PI controllers. These external controllers are not the focus of this study.

\section{Design the Current Controller of Battery Energy Storage System Using Energy-Based and Proportional-Integral Regulator}

EB control is built on passivity theory. According to the definition above, the BESS is obviously a passive system, and this is because if no energy is supplemented from the power grid, the BESS will 
eventually run to the lowest energy point owing to the dissipation. Consequently, the EB method can be applied in BESSs naturally. In this section, the detailed step-by-step design method of EB control in a BESS is proposed. The design method of the conventional PI controller used for comparison is briefly presented too.

\subsection{Design of the Energy-Based Controller Adopting the Interconnection and Damping Assignment Strategy}

The input of the EB controller is the power reference $P^{*}$ and $Q^{*}$. By the current closed-loop regulation, the EB method can control the BESS power tracking with the reference power. The BESS controlled by the EB method can apply to ordinary AC MG situations. For one, BESS control is relatively independent of the power generations. Hence EB control can be implemented in different renewable production situations such as wind turbine and photovoltaic power sources. For another, BESS control is essentially a power regulation issue. In the grid-connected mode, BESS power is utilized to smooth the renewable generation output. In the islanded mode, the power references are generated by the external $f-p$ and $v-q$ PI controllers, which has been illustrated in Figure 2 .

The process of configuring the closed-loop system is called energy shaping in the EB control method. In this study, we adopt the IDA energy shaping strategy which is easy to implement and has respectable performance. The design of the EB controller using the IDA strategy consists of the following steps.

\subsubsection{Battery Energy Storage System Modeling}

The EB controller design depends on the topology of the BESS. The d-q axis mathematical model for BESS as shown in Figure 2 is provided in Equation (2). It should be noted that the mathematical model could be different according to the converter system. Nevertheless, the design process of EB control for a BESS is similar and can be extended to the general MG configurations:

$$
\left\{\begin{aligned}
L_{\mathrm{g}} \frac{d i_{\mathrm{gd}}}{d t} & =-R_{\mathrm{g}} i_{\mathrm{gd}}+\omega L_{\mathrm{g}} i_{\mathrm{gq}}-s_{\mathrm{d}} u_{\mathrm{dc}}+u_{\mathrm{gd}} \\
L_{\mathrm{g}} \frac{d i_{\mathrm{gq}}}{d t} & =-R_{\mathrm{g}} i_{\mathrm{gq}}-\omega L_{\mathrm{g}} i_{\mathrm{gd}}-s_{\mathrm{q}} u_{\mathrm{dc}}+u_{\mathrm{gq}} \\
C \frac{d u_{\mathrm{dc}}}{d t} & =\frac{3}{2} s_{\mathrm{d}} i_{\mathrm{gd}}+\frac{3}{2} s_{\mathrm{q}} i_{\mathrm{gq}}+\frac{E_{\mathrm{g}}-u_{\mathrm{dc}}}{R_{\mathrm{b}}}
\end{aligned}\right.
$$

According to the IDA strategy, we need to describe a nonlinear system such as a BESS in the PCH model as:

$$
\left\{\begin{array}{l}
\dot{x}=[J(x)-R(x)] \frac{\partial H(x)}{\partial x}+g(x) u \\
y=g^{\mathrm{T}}(x) \frac{\partial H(x)}{\partial x}
\end{array}\right.
$$

In the PCH model, the binary product of $u$ and $y$ reflects the power of the system to interact with the outside. $R(x)=R^{\mathrm{T}}(x)>0$, is the internal dissipation matrix which reflects the damping characteristics of the system. $J(x)$ and $g(x)$ reveal the structural features of the system. $H(x)$ describes the total stored energy in the system.

Comparing Equations (2) with (3), we can construct the PCH model for BESS as follows:

$$
\begin{aligned}
& \left\{\begin{array}{l}
x=\left[\begin{array}{lll}
L_{\mathrm{g}} i_{\mathrm{gd}} & L_{\mathrm{g}} i_{\mathrm{gq}} & \frac{2}{3} C u_{\mathrm{dc}}
\end{array}\right]^{\mathrm{T}} \\
u=\left[\begin{array}{lll}
u_{\mathrm{gd}} & u_{\mathrm{gq}} & \frac{2 E_{\mathrm{g}}}{3 R_{\mathrm{b}}}
\end{array}\right]^{\mathrm{T}}, y=\left[\begin{array}{lll}
i_{\mathrm{gd}} & i_{\mathrm{gq}} & u_{\mathrm{dc}}
\end{array}\right]^{\mathrm{T}}
\end{array}\right. \\
& \left\{\begin{array}{l}
H=\frac{1}{2} L_{\mathrm{g}} i_{\mathrm{gd}}^{2}+\frac{1}{2} L_{\mathrm{g}} i_{\mathrm{gq}}^{2}+\frac{1}{2}\left(\frac{2}{3} C\right) u_{\mathrm{dc}}^{2} \\
\nabla H=\left[\begin{array}{lll}
i_{\mathrm{gd}} & i_{\mathrm{gq}} & u_{\mathrm{dc}}
\end{array}\right]^{\mathrm{T}}
\end{array}\right.
\end{aligned}
$$




$$
J=\left[\begin{array}{ccc}
0 & \omega L_{\mathrm{g}} & -s_{\mathrm{d}} \\
-\omega L_{\mathrm{g}} & 0 & -s_{\mathrm{q}} \\
s_{\mathrm{d}} & s_{\mathrm{q}} & 0
\end{array}\right], g=\left[\begin{array}{ccc}
1 & 0 & 0 \\
0 & 1 & 0 \\
0 & 0 & 1
\end{array}\right], R=\left[\begin{array}{ccc}
R_{\mathrm{g}} & 0 & 0 \\
0 & R_{\mathrm{g}} & 0 \\
0 & 0 & \frac{2}{3 R_{\mathrm{b}}}
\end{array}\right]
$$

\subsubsection{The Balance Point Establishment}

A Hamilton function $H_{\mathrm{d}}(x)$ is constructed, and it will obtain minimum at the equilibrium point $x^{*}$. Meanwhile, it is the desired energy function with the closed-loop feedback. In EB control, the input is $u=\alpha(x)$, and we should make the closed loop dissipative system as:

$$
\begin{aligned}
& \dot{x}=\left[J_{\mathrm{d}}(x)-R_{\mathrm{d}}(x)\right] \frac{\partial H_{\mathrm{d}}(x)}{\partial x} \\
& \left\{\begin{array}{l}
J_{\mathrm{d}}(x)=J(x)+J_{\mathrm{a}}(x)=-J_{\mathrm{d}}^{\mathrm{T}}(x) \\
R_{\mathrm{d}}(x)=R(x)+R_{\mathrm{a}}(x)=R_{\mathrm{d}}^{\mathrm{T}}(x)>0 \\
H_{\mathrm{d}}(x)=H(x)+H_{\mathrm{a}}(x)
\end{array}\right.
\end{aligned}
$$

In Equation (7), $H_{\mathrm{a}}(x)$ is a function to be determined, which is the injected energy by the control to make the system stable at the equilibrium point. To meet the above requirements, we construct the $H_{\mathrm{d}}(x)$ in BESS as:

$$
\left\{\begin{array}{c}
H_{\mathrm{d}}=\frac{1}{2} L_{\mathrm{g}}\left(i_{\mathrm{gd}}-i_{\mathrm{gd}}^{*}\right)^{2}+\frac{1}{2} L_{\mathrm{g}}\left(i_{\mathrm{gq}}-i_{\mathrm{gq}}^{*}\right)^{2}+\frac{1}{2}\left(\frac{2}{3} C\right)\left(u_{\mathrm{dc}}-u_{\mathrm{dc}}^{*}\right)^{2} \\
\nabla H_{\mathrm{d}}=\left[\begin{array}{ccc}
i_{\mathrm{gd}}-i_{\mathrm{gd}}^{*} & i_{\mathrm{gq}}-i_{\mathrm{gq}}^{*} & u_{\mathrm{dc}}-u_{\mathrm{dc}}^{*}
\end{array}\right]^{\mathrm{T}}
\end{array}\right.
$$

The gradient instead of the partial derivative of $x$ is employed in the equation. The BESS current reference in the $d-q$ frame can be directly acquired by the power reference, which has been provided in Equation (1). The other equilibrium points of the system can be obtained by:

$$
\left.\dot{x}\right|_{x=x^{*}}=0 \Rightarrow \frac{\partial H_{\mathrm{d}}\left(x^{*}\right)}{\partial x}=0
$$

From Equations (1), (2) and (9) we can gain the other balance points of the system:

$$
\left\{\begin{array}{c}
u_{\mathrm{dc}}^{*}=\frac{E_{\mathrm{g}}+\sqrt{E_{\mathrm{g}}^{2}-6 R_{\mathrm{b}} R_{\mathrm{g}}\left(i_{\mathrm{gd}}^{* 2}+i_{\mathrm{gq}}^{* 2}\right)+4 R_{\mathrm{b}} P^{*}}}{2} \\
s_{\mathrm{d}}^{*}=\frac{-R_{\mathrm{g}} i_{\mathrm{gd}}^{*}+\omega L_{\mathrm{g}} i_{\mathrm{gq}}^{*}+u_{\mathrm{gd}}}{u_{d c}^{*}} \\
s_{\mathrm{q}}^{*}=\frac{-R_{\mathrm{g}} i_{\mathrm{gq}}^{*}-\omega L_{\mathrm{g}} i_{\mathrm{gd}}^{*}+u_{\mathrm{gq}}}{u_{\mathrm{dc}}^{*}}
\end{array}\right.
$$

\subsubsection{The Configuration of Undetermined Function}

The suitable $J_{\mathrm{a}}(x)$ and $R_{\mathrm{a}}(x)$ should be identified and meet the demand of IDA strategy. Comparing the simultaneous Equations (3) and (7), and the result after simplification is:

$$
\left(J_{\mathrm{d}}-R_{\mathrm{d}}\right)\left(-\nabla H_{\mathrm{a}}\right)=\left(J_{\mathrm{a}}-R_{\mathrm{a}}\right) \nabla H-g u
$$

Equation (11) is critical in the EB method design, which is used to solve the undetermined coefficients. The undetermined functions in EB controller of BESS are chosen as: 


$$
J_{\mathrm{a}}=\left[\begin{array}{ccc}
0 & 0 & A_{1} \\
0 & 0 & A_{2} \\
-A_{1} & -A_{2} & 0
\end{array}\right], R_{\mathrm{a}}=\left[\begin{array}{ccc}
R_{1} & 0 & 0 \\
0 & R_{1} & 0 \\
0 & 0 & R_{2}
\end{array}\right]
$$

Taking the above equations into Equation (11), and after arranging we can get:

$$
\begin{aligned}
& \left\{\begin{array}{l}
s_{\mathrm{d}}=s_{\mathrm{d}}^{*}+\frac{R_{1}\left(i_{\mathrm{gd}}-i_{\mathrm{gd}}^{*}\right)-A_{1}\left(u_{\mathrm{dc}}-u_{\mathrm{dc}}^{*}\right)}{u_{\mathrm{dc}}^{*}} \\
s_{\mathrm{q}}=s_{\mathrm{q}}^{*}+\frac{R_{1}\left(i_{\mathrm{gq}}-i_{\mathrm{gq}}^{*}\right)-A_{2}\left(u_{\mathrm{dc}}-u_{\mathrm{dc}}^{*}\right)}{u_{\mathrm{dc}}^{*}}
\end{array}\right. \\
& \frac{R_{1} i_{\mathrm{gd}}^{*}\left(i_{\mathrm{gd}}-i_{\mathrm{gd}}^{*}\right)-A_{1} i_{\mathrm{gd}}^{*}\left(u_{\mathrm{dc}}-u_{\mathrm{dc}}^{*}\right)+R_{1} i_{\mathrm{gq}}^{*}\left(i_{\mathrm{gq}}-i_{\mathrm{gq}}^{*}\right)-A_{2} i_{\mathrm{gq}}^{*}\left(u_{\mathrm{dc}}-u_{\mathrm{dc}}^{*}\right)}{u_{d c}^{*}}+A_{1}\left(i_{\mathrm{gd}}-i_{\mathrm{gd}}^{*}\right) \\
& +A_{2}\left(i_{\mathrm{gq}}-i_{\mathrm{gq}}^{*}\right)+R_{2}\left(u_{\mathrm{dc}}-u_{\mathrm{dc}}^{*}\right)=0
\end{aligned}
$$

The selection of undetermined coefficients should simplify the formula and meet the Equation (14). Finally, through observation, we choose:

$$
\left\{\begin{array}{c}
A_{1}=\frac{-R_{1} i_{\mathrm{gd}}^{*}}{u_{\mathrm{dc}}^{*}}, A_{2}=\frac{-R_{1} i_{\mathrm{gq}}^{*}}{u_{\mathrm{dc}}^{*}} \\
R_{1}=\frac{2 u_{\mathrm{dc}}^{* 2}}{3 R_{\mathrm{b}}\left(i_{\mathrm{gd}}^{* 2}+i_{\mathrm{gq}}^{* 2}\right)}, R_{2}=-\frac{2}{3 R_{\mathrm{b}}}
\end{array}\right.
$$

\subsubsection{Stability Analysis}

Stability issues should be considered for a controller. In order to examine the stability of the EB method, the Lyapunov second method is employed in this study. Considering that $H_{\mathrm{d}}$ is a positive definite energy function which is only equal to zero at the equilibrium point, it can be chosen as Lyapunov function directly, and this will simplify the stability analysis significantly. The stability of the system is dependent on the first order derivative of $H_{\mathrm{d}}$ :

$$
\frac{d H_{\mathrm{d}}}{d t}=\left[\nabla H_{\mathrm{d}}\right]^{\mathrm{T}} \dot{x}=\left[\nabla H_{\mathrm{d}}\right]^{\mathrm{T}}\left(J_{\mathrm{d}}-R_{\mathrm{d}}\right) \nabla H_{\mathrm{d}}
$$

Because $J_{\mathrm{d}}$ is a skew symmetric matrix, then $\left[\nabla H_{\mathrm{d}}\right]^{\mathrm{T}} J_{\mathrm{d}} \nabla H_{\mathrm{d}} \equiv 0$. Considering that $R_{\mathrm{d}}$ is positive symmetric matrix, it can be readily obtained:

$$
\frac{d H_{\mathrm{d}}}{d t}=\left[\nabla H_{\mathrm{d}}\right]^{\mathrm{T}} \dot{x}=-\left[\nabla H_{\mathrm{d}}\right]^{\mathrm{T}} R_{\mathrm{d}} \nabla H_{\mathrm{d}} \leq 0
$$

The derivative of $H_{\mathrm{d}}$ is negative and only equal to zero at the equilibrium point. Judging by Lyapunov second method, the balance point is asymptotically stable. Furthermore, it is evident that when $\|x\| \rightarrow \infty, H_{\mathrm{d}} \rightarrow \infty$. Hence a large range of asymptotic stability is achieved at the equilibrium point. It is remarkable that exceptional stability is a significant advantage for the EB method.

\subsection{Combining Integral Operation}

EB control may have static errors due to the impact of model errors and noise. Based on [29], the integral action is combined to resolve this problem and increase the robustness of the system. Considering that the control variables are $s_{\mathrm{d}}$ and $s_{\mathrm{q}}$, we need to change the positions of $s_{\mathrm{d}}$ and $s_{\mathrm{q}}$ from the internal structure matrix $J$ to control the input $u$. 


$$
\begin{aligned}
&\left\{\begin{array}{l}
\dot{x}=(J-R) \nabla H+g u=\left(J_{\text {new }}-R\right) \nabla H+g_{1} u_{1}+g_{2} u_{2} \\
y_{1}=g_{1}^{\mathrm{T}} \nabla H \\
y_{2}=g_{2}^{\mathrm{T}} \nabla H
\end{array}\right. \\
& g_{1}=g=\left[\begin{array}{lll}
1 & 0 & 0 \\
0 & 1 & 0 \\
0 & 0 & 1
\end{array}\right], g_{2}=\left[\begin{array}{cc}
-u_{\mathrm{dc}} & 0 \\
0 & -u_{\mathrm{dc}} \\
i_{\mathrm{gd}} & i_{\mathrm{gq}}
\end{array}\right], J_{\text {new }}=\left[\begin{array}{ccc}
0 & \omega L_{\mathrm{g}} & 0 \\
-\omega L_{\mathrm{g}} & 0 & 0 \\
0 & 0 & 0
\end{array}\right] \\
&\left\{\begin{array}{c}
u_{1}=u=\left[\begin{array}{lll}
u_{\mathrm{gd}} & u_{\mathrm{gq}} & \frac{2 E_{\mathrm{g}}}{3 R_{\mathrm{b}}}
\end{array}\right]^{\mathrm{T}}, u_{2}=\left[\begin{array}{ll}
s_{\mathrm{d}} & s_{\mathrm{q}}
\end{array}\right]^{\mathrm{T}} \\
y_{1}=y=\left[\begin{array}{lll}
i_{\mathrm{gd}} & i_{\mathrm{gq}} & u_{\mathrm{dc}}
\end{array}\right]^{\mathrm{T}}, y_{2}=\left[\begin{array}{ll}
0 & 0
\end{array}\right]^{\mathrm{T}}
\end{array}\right.
\end{aligned}
$$

Define $y_{2 \mathrm{~d}}=g_{2}^{\mathrm{T}} \nabla H_{\mathrm{d}}$. From Equation (8), it can be found $\nabla H_{\mathrm{d}}$ stands for the error. Hence we add a term as follows:

$$
Z=-K_{\mathrm{I}} \int y_{2 \mathrm{~d}} d t=-K_{\mathrm{I}} \int g_{2}^{\mathrm{T}} \nabla H_{\mathrm{d}} d t
$$

In Equation (21), $Z$ is the integral of error. It is evident that $\dot{Z}=-K_{\mathrm{I}} g_{2}^{\mathrm{T}} \nabla H_{\mathrm{d}}$. When $\dot{Z}$ tends to zero, there is no steady error. Define:

$$
\left\{\begin{array}{c}
H_{\mathrm{dZ}}=\frac{Z^{\mathrm{T}} K_{\mathrm{I}}^{-1} Z}{2} \\
H_{\mathrm{T}}(x, Z)=H_{\mathrm{d}}(x)+H_{\mathrm{dZ}}(Z)
\end{array}\right.
$$

Now a new extended PCH model is constructed:

$$
\left[\begin{array}{c}
\dot{x} \\
\dot{Z}
\end{array}\right]=\left[\begin{array}{cc}
J_{\mathrm{d}}-R_{\mathrm{d}} & K_{\mathrm{I}} g_{2} \\
-K_{\mathrm{I}} g_{2}^{\mathrm{T}} & 0
\end{array}\right]\left[\begin{array}{c}
\frac{\partial H_{\mathrm{T}}(x, Z)}{\partial x} \\
\frac{\partial H_{\mathrm{T}}(x, Z)}{\partial \mathrm{Z}}
\end{array}\right]
$$

Also, it can be obtained that:

$$
\left\{\begin{array}{l}
\frac{\partial H_{\mathrm{T}}(x, Z)}{\partial x}=\nabla H_{\mathrm{d}} \\
\frac{\partial H_{\mathrm{T}}(x, Z)}{\partial Z}=K_{\mathrm{I}}^{-1} Z
\end{array}\right.
$$

According to [29], all of the stability properties of $x^{*}$ in the original $\mathrm{PCH}$ system are preserved in the new extended PCH system. For this extended PCH system:

$$
\left[\begin{array}{c}
s_{\text {dnew }} \\
s_{\text {qnew }}
\end{array}\right]=\left[\begin{array}{c}
s_{\mathrm{d}} \\
s_{\mathrm{q}}
\end{array}\right]+Z=\left[\begin{array}{c}
s_{\mathrm{d}} \\
s_{\mathrm{q}}
\end{array}\right]-K_{\mathrm{I}} \int g_{2}^{\mathrm{T}} \nabla H_{\mathrm{d}} d t
$$

After substitution, finally we can obtain:

$$
\left\{\begin{array}{l}
s_{\text {dnew }}=s_{\mathrm{d}}+K_{\mathrm{I}} \int u_{\mathrm{dc}}\left(i_{\mathrm{gd}}-i_{\mathrm{gd}}^{*}\right) d t-K_{\mathrm{I}} \int i_{\mathrm{gd}}\left(u_{\mathrm{dc}}-u_{\mathrm{dc}}^{*}\right) d t \\
s_{\mathrm{qnew}}=s_{\mathrm{q}}+K_{\mathrm{I}} \int u_{\mathrm{dc}}\left(i_{\mathrm{gq}}-i_{\mathrm{gq}}^{*}\right) d t-K_{\mathrm{I}} \int i_{\mathrm{gq}}\left(u_{\mathrm{dc}}-u_{\mathrm{dc}}^{*}\right) d t
\end{array}\right.
$$

It is worthwhile pointing out that the selection of $K_{\mathrm{I}}$ only depends on the static error. On the whole, the primary disadvantage of EB strategy is that the initial design process of EB method is a little complex and requires experience. However, the implementation of EB method is very straightforward due to the small amount of calculation. Taken together, it is very suitable for multi-input/multi-output system like BESS. 


\subsection{Design of Proportional-Integral Controller}

As a contrast to the EB method, the conventional PI controller should be carefully designed. The control diagram of the system in the d-q frame is illustrated in Figure 3. In the actuator, there are two unfavorable factors for the control, which can be seen in Figure 3. One is the coupling characteristics of the BESS current between $\mathrm{d}$ and $\mathrm{q}$ axis, and this will lead to the difficulties for the controller design. Another one is that the grid voltage is a disturbance for the BESS current control, which will deteriorate the transient performance of the system. To resolve these problems, we adopt the classic current feedforward decoupling PI control strategy [30]. In Figure 3, $e$ is the current tracking error. After a PI regulator, we decouple the BESS current control in the $\mathrm{d}$-q frame and feed forward the grid voltage $u_{\mathrm{g}}$ to restrain the disturbance. $v$ is the sum of PI regulator output and feedforward decoupling part. Considering that VSC is equivalent to a proportional amplification, to simplify the design, we divide $v$ by the magnification $u_{\mathrm{dc}} / 2$ to gain the duty ratio $s$, and this will make the equivalent PWM magnification $k_{\mathrm{PWM}}=1 . u_{\mathrm{t}}$ is the output voltage of VSC.

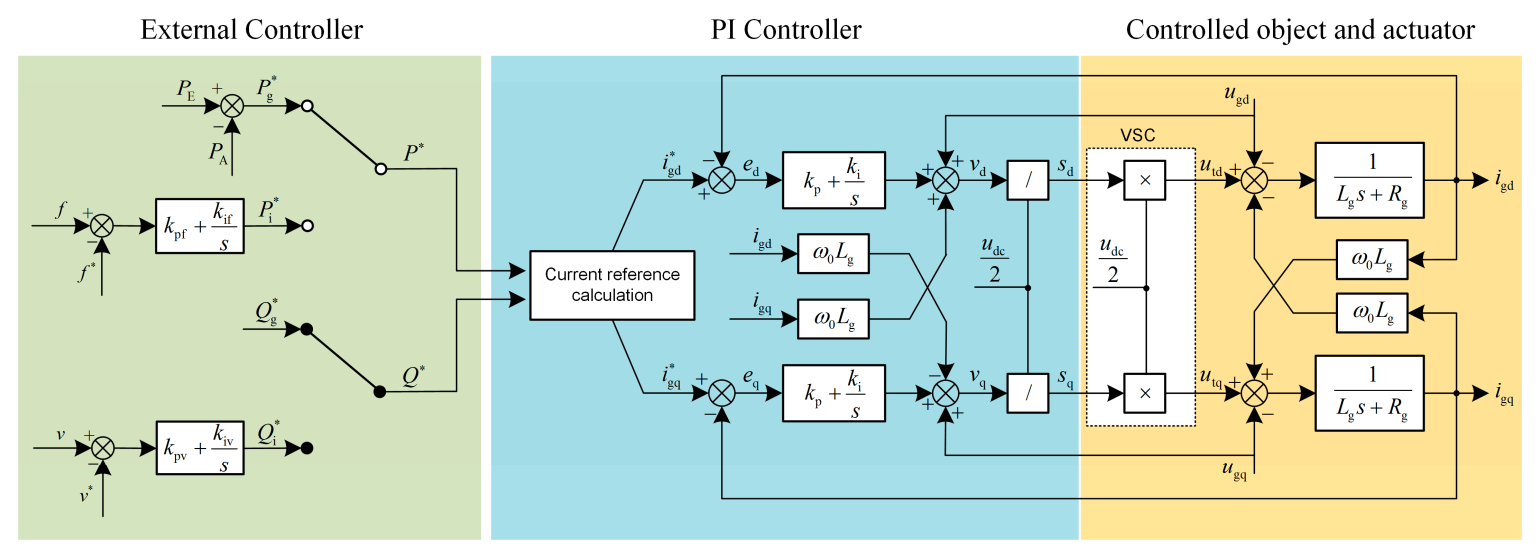

Figure 3. The control diagram of system using proportional-integral (PI) method.

The classic PI parameter tuning method provided by [30] is employed in this study. The crucial idea is that PI controller should cancel the adverse pole $R_{\mathrm{g}} / L_{\mathrm{g}}$. In particular, if the damping ratio $\xi$ is chosen as 0.707 , PI parameters can be obtained as follows:

$$
k_{\mathrm{p}}=\frac{L_{\mathrm{g}}}{3 T_{\mathrm{s}}}, k_{\mathrm{i}}=\frac{R_{\mathrm{g}}}{3 T_{\mathrm{s}}}
$$

The closed-loop transfer function is typical second order system, and the key technical indicators can be derived easily. Specifically, the overshoot is $4.3 \%$; the phase margin is $65.5^{\circ}$; the rise time is $7.08 T_{\mathrm{s}}$, and the sheared frequency is $0.303 / T_{\mathrm{s}}$. Overall, the system has good tracking performance and stability.

\section{Case Study Results and Discussions}

To verify the performance of EB control, we implemented a detailed case simulation study using the Matlab/Simulink software (MathWorks, Natick, MA. USA). In this study, conventional PI control is employed for comparison. The PI coefficients are carefully designed by the classic parameter tuning method proposed in [30]. In the simulation, we adopt the fixed-step and ode3 algorithm. The total simulation time is $20 \mathrm{~s}$. Before $1 \mathrm{~s}$, the converter is not working and this period is long enough for the phase locked loop (PLL) to stabilize. At $1 \mathrm{~s}$, the converter begins to work. The other related parameters in the simulation are listed in Table 1. 
Table 1. The main simulation parameters.

\begin{tabular}{cc}
\hline Parameter Name & Parameter Value \\
\hline Sampling/switching frequency & $10 \mathrm{kHz} / 10 \mathrm{kHz}$ \\
Battery nominal/fully-charged voltage & $800 \mathrm{~V} / 931.2 \mathrm{~V}$ \\
$C, R_{\mathrm{b}}$ & $1000 \mu \mathrm{F}, 0.16 \Omega$ \\
$L_{\mathrm{g}}, R_{\mathrm{g}}$ & $1 \mathrm{mH}, 1.1 \mathrm{~m} \Omega$ \\
$P_{\mathrm{E}}$ & $300 \mathrm{~kW}$ \\
$K_{\mathrm{I}}$ & 0.2 \\
$k_{\mathrm{p}}, k_{\mathrm{i}}$ & $3.333,3.667$ \\
$k_{\mathrm{pf}}, k_{\mathrm{if}} 1$ & $0.3,0.4$ \\
$k_{\mathrm{pv}}, k_{\mathrm{iv}}{ }^{1}$ & $0.002,0.001$ \\
\hline &
\end{tabular}

Several scenarios are considered for the test MG system, including the step power tracking, ramp power tracking, grid-connected mode and islanded mode. Robustness to the parameter uncertainty must be tested due to the inevitable model mismatch. In this study, we consider two different parameter cases of $L_{\mathrm{g}}$ and $R_{\mathrm{g}}$. This is mainly because it is relatively difficult to obtain accurate values for these two time-variant parameters and sometimes we even change the inductance actively to improve the performance. The result comparison of some important performance indexes in the case study is listed in Table A1 as a supplement for the simulation figure results. After the case study, we provide a sensibility analysis to test and discuss the sensitivity of the system to the parameters.

\subsection{Step Response Test}

This scenario is used to test the control performance of the converter. In this scenario, the reference power is zero at first and changes to be $-20,40 \mathrm{~kW}$ at timepoints of $8 \mathrm{~s}$ and $14 \mathrm{~s}$, respectively. Two different parameter cases are considered. Case A1 is the model match situation which means $L_{\mathrm{g}}=1 \mathrm{mH}$ and $R_{\mathrm{g}}=1.1 \mathrm{~m} \Omega$. Case A2 is the model mismatch situation of $L_{\mathrm{g}}=4 \mathrm{mH}$ and $R_{\mathrm{g}}=0.2 \Omega$.

Figure $4 \mathrm{a}, \mathrm{b}$ shows the step response of the PI and EB methods in the case A1. It can be seen that both of them can track the step reference with no steady error. However, some details merit further consideration. Firstly, at $1 \mathrm{~s}$, when the converter starts to work, it is equivalent to a controller disturbance. At this time, the PI method generates a larger overshoot and needs a long recovery process which lasts nearly $2.5 \mathrm{~s}$. This period is defined as the adjusting time. On the contrary, the overshoot of the EB method is smaller, and the recovery process is less than $0.05 \mathrm{~s}$. Therefore the EB method has a better anti-disturbance performance than the PI method. Secondly, both approaches can track the step reference with a very fast speed (less than $0.02 \mathrm{~s}$ ) and virtually no overshoots exist. However, the PI method still needs some time to eliminate the steady error (this can be seen at $14 \mathrm{~s}$ ), whereas the EB method avoids this process entirely. Finally, the EB method has a smoother stable performance which can be observed in the enlarged figure, and this also suggests that relatively small low-frequency harmonic and ripple peak values can be achieved by the EB method. It is worth noting that the dominant harmonic frequency of the EB method is higher than that of the PI method, whereas some additional filter device can easily absorb high-frequency ripples.

Figure $4 \mathrm{c}, \mathrm{d}$ provides the step response in the case A2. It can be observed that the EB method maintains its exceptional performance both in the transient and steady state. On the contrary, the PI method has a worse recovery process compared with Figure $4 \mathrm{a}$. The overshoot increases to $-36 \mathrm{~kW}$ and the adjusting time extends to nearly $4 \mathrm{~s}$. At $14 \mathrm{~s}$ the PI method presents a slower tracking process. 


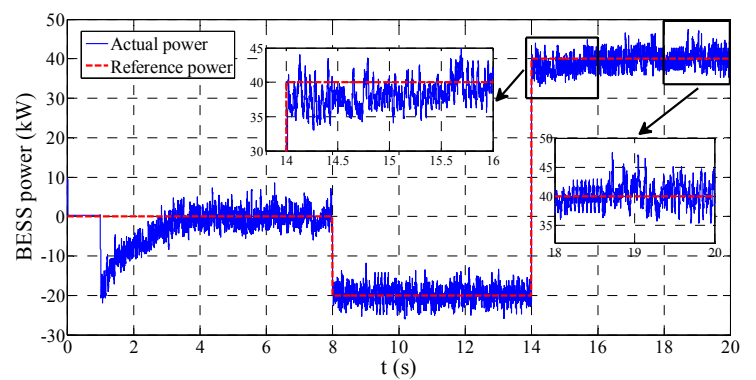

(a)

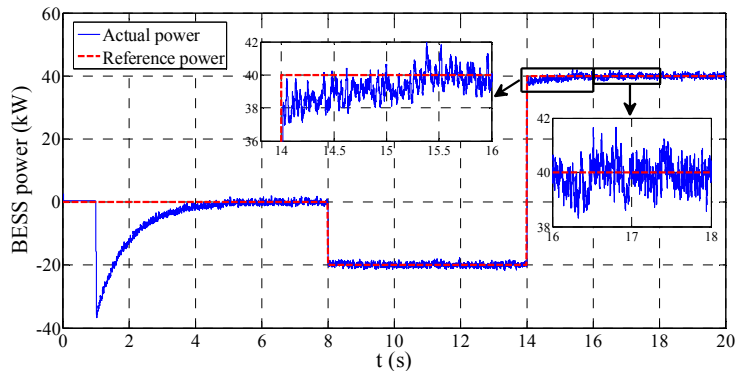

(c)

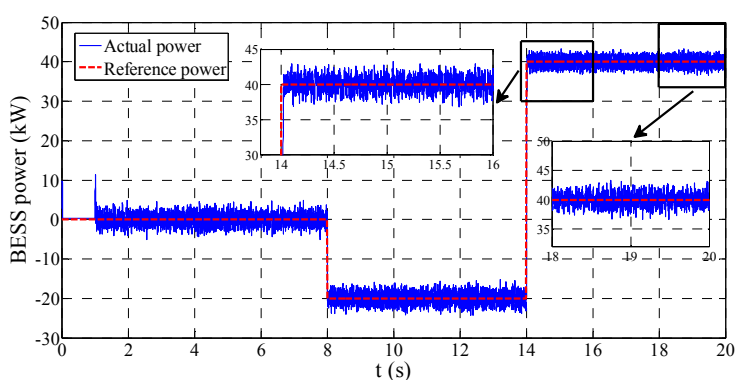

(b)

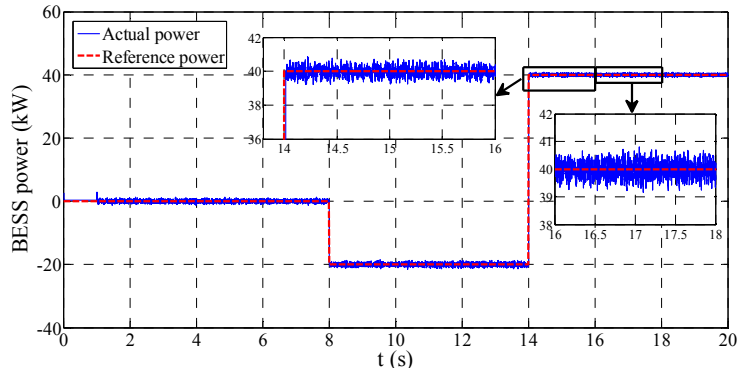

(d)

Figure 4. Step response of controller. (a) PI method (case A1); (b) EB method (case A1); (c) PI method (case A2); and (d) EB method (case A2).

Figure 5a provides the power overshoot (at $1 \mathrm{~s}$ ) when $L_{\mathrm{g}}$ changes and $R_{\mathrm{g}}$ is fixed to $1.1 \mathrm{~m} \Omega$. Figure $5 \mathrm{~b}$ shows the adjusting time when $R_{\mathrm{g}}$ changes and $L_{\mathrm{g}}$ is fixed to $1 \mathrm{mH}$. It can be found that the performance of the PI method is significantly affected by the parameter change whereas EB method has a superior robustness to parameter uncertainty.

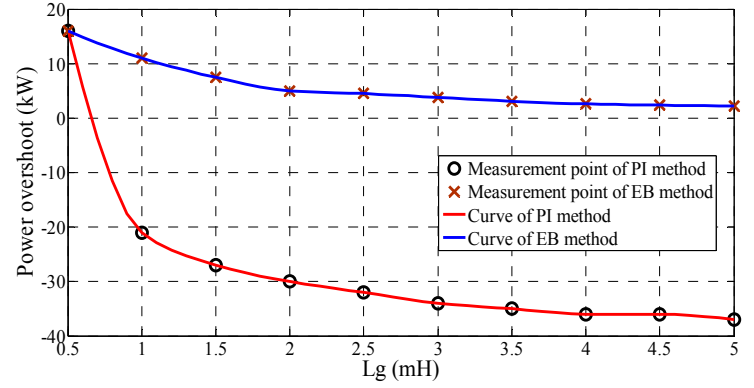

(a)

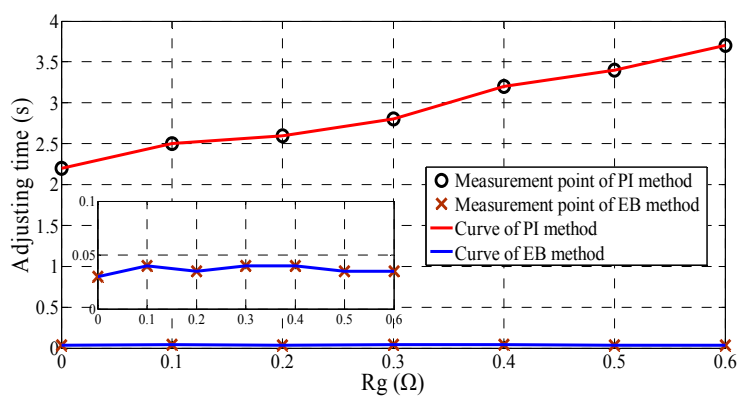

(b)

Figure 5. Curves when parameters change (Step response). (a) The overshoot when $L_{\mathrm{g}}$ changes and $R_{\mathrm{g}}=1.1 \mathrm{~m} \Omega$; and (b) adjusting time when $R_{\mathrm{g}}$ changes and $L_{\mathrm{g}}=1 \mathrm{mH}$.

\subsection{Ramp Response Test}

This scenario is also used to test the control performance of the converter. The converter starts at $1 \mathrm{~s}$, and the reference gradually increases with the slope of $10 \mathrm{~kW} / \mathrm{s}$. Case B1 is the situation of $L_{\mathrm{g}}=1 \mathrm{mH}$ and $R_{\mathrm{g}}=1.1 \mathrm{~m} \Omega$. Case B2 is the condition of $L_{\mathrm{g}}=4 \mathrm{mH}$ and $R_{\mathrm{g}}=0.2 \Omega$. Figure 6 compares the slope response performance of PI and EB methods in these two cases.

It can be seen that the EB method has evidently better tracking ability compared with the PI method. Additionally, the EB method can maintain its satisfactory performance when the parameters vary. Conversely, the performance of the PI method has a significant change both in overshoot and adjusting time. 


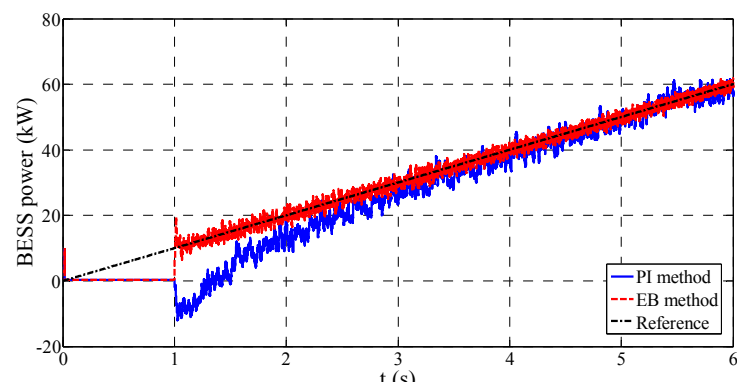

(a)

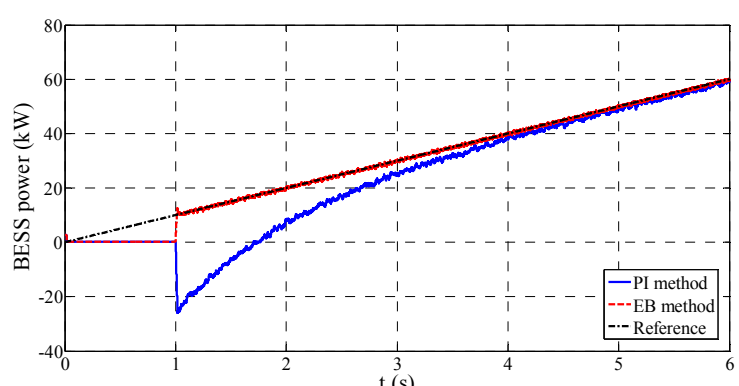

(b)

Figure 6. Ramp response of controller. (a) Case B1; and (b) case B2.

\subsection{Grid-Connected Mode Test}

Figure 7 shows the power of some main parts of the MG in grid-connected mode test. In this scenario, the fluctuation of the wind generation power is illustrated in Figure 7. We have defined the charging direction of $P_{\mathrm{B}}$ is positive as shown in Figure 1. Hence the fluctuation of $P_{\mathrm{B}}$ has the same direction with that of wind generation. The load includes linear and nonlinear parts. Linear part is the resistor of $350 \mathrm{~kW}$, and the nonlinear element is a capacitor filtered diode rectifier circuit with a $4 \Omega$ resistor in DC side. Case C1 is the model match situation which means $L_{\mathrm{g}}=1 \mathrm{mH}$ and $R_{\mathrm{g}}=1.1 \mathrm{~m} \Omega$. Case $\mathrm{C} 2$ is the model mismatch situation of $L_{\mathrm{g}}=4 \mathrm{mH}$ and $R_{\mathrm{g}}=0.2 \Omega$.

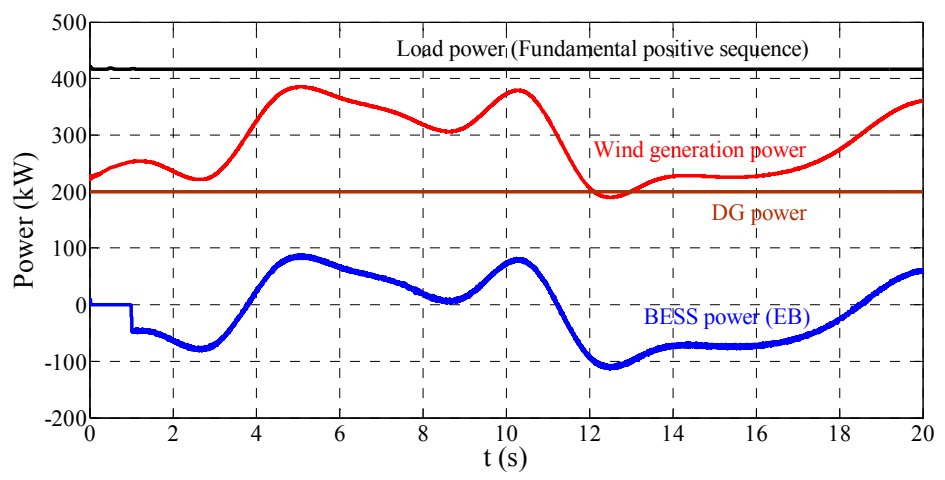

Figure 7. The power of some main parts of MG (grid-connected mode).

Figure 8a,b compares the performance of smoothing the fluctuations in wind generation between the EB and PI methods in the case C1. When the converter starts to work at $1 \mathrm{~s}$, the PI method has a disturbance recovery process and the adjusting time is about $2.7 \mathrm{~s}$, whereas the EB method goes into the steady state very fast and almost no overshoot exists.

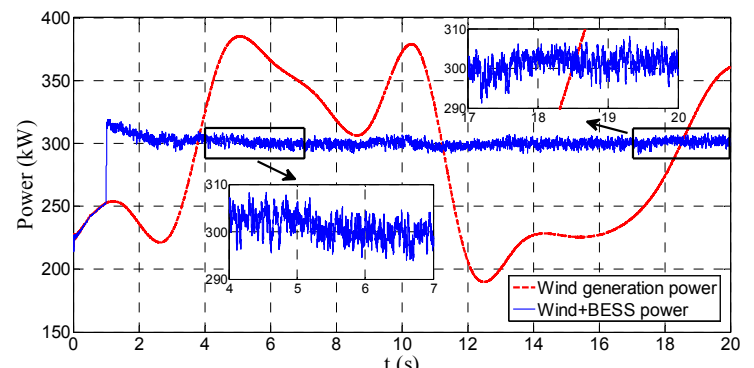

(a)

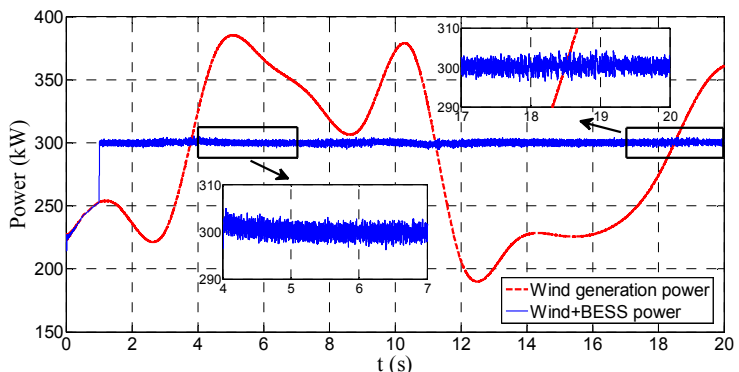

(b)

Figure 8. Cont. 


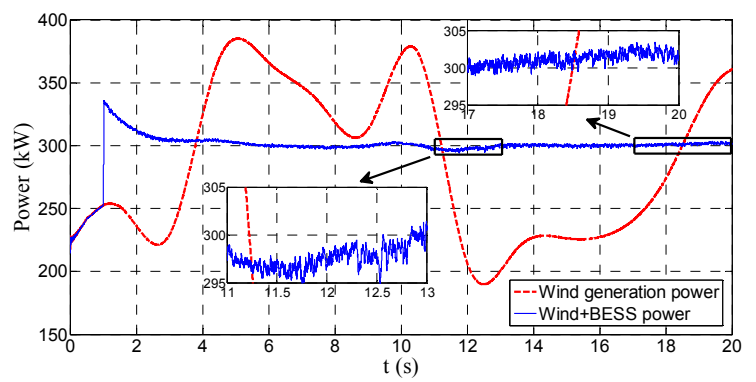

(c)

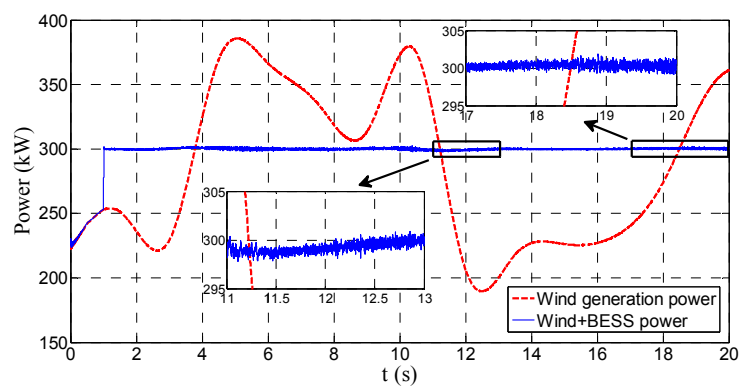

(d)

Figure 8. Performance on power smoothing. (a) PI method (case C1); (b) EB method (case C1); (c) PI method (case C2); and (d) EB method (case C2).

Furthermore, when the PI method is in the steady state, it shows an obvious slight low-frequency fluctuation. However, the EB method provides a much smoother performance. Figure 8c,d shows the smoothing performance in the case C2. The EB method keeps the good performance whereas the performance of the PI method is unsatisfactory. It can be noticed that smoothed power of EB method is much flatter than that of the PI method. Moreover, the overshoot of the PI method at $1 \mathrm{~s}$ increases to be near $36 \mathrm{~kW}$ and the adjusting time is over $4 \mathrm{~s}$. Figure $9 \mathrm{a}, \mathrm{b}$ provides the overshoot and adjusting time when $L_{\mathrm{g}}$ and $R_{\mathrm{g}}$ vary, respectively. It can be found that the EB method has a better robustness to parameter uncertainty and the parameters greatly influence the performance of the PI method.

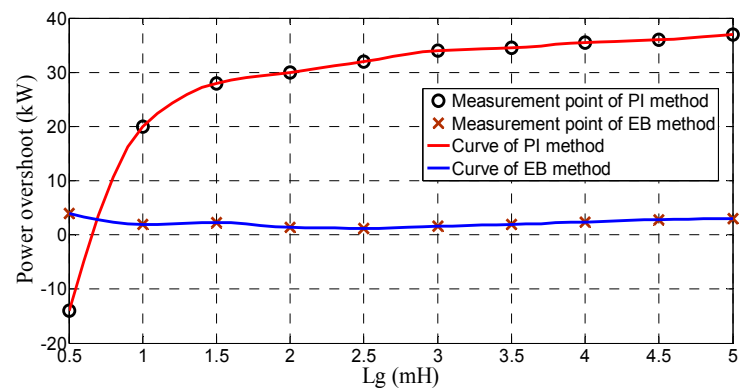

(a)

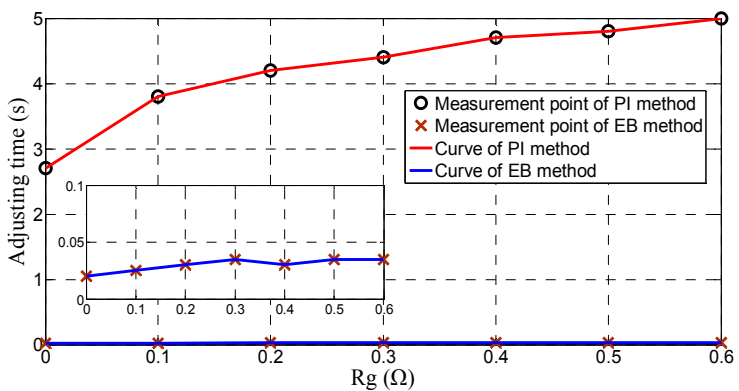

(b)

Figure 9. Curves when parameters change (the smoothed power). (a) The overshoot when $L_{\mathrm{g}}$ changes and $R_{\mathrm{g}}=1.1 \mathrm{~m} \Omega$; and (b) adjusting time when $R_{\mathrm{g}}$ changes and $L_{\mathrm{g}}=1 \mathrm{mH}$.

Figure 10 provides the comparison of the low-frequency ripple of the smoothed power between the PI and EB methods during $12-20 \mathrm{~s}$ in cases $\mathrm{C} 1$ and $\mathrm{C} 2$. It can be seen that the smoothed power of the PI method has much more low-frequency ripples than that of the EB method, and this is mainly because the tracking ability of the PI method is insufficient, especially when wind generation changes steeply. In the case C1, the total ripple root mean square (RMS) value of smoothed power by the PI method is $2.5 \mathrm{~kW}$, whereas it decreases to $1.05 \mathrm{~kW}$ by the EB method. In the case C2, the whole ripple RMS value of smoothed power by the PI method is $1.6 \mathrm{~kW}$, whereas it is only $0.6 \mathrm{~kW}$ for the EB method. Also, it is found that the EB method has a smaller peak ripple value compared to the PI method.

Figure 11 depicts the power tracking performance in the case $\mathrm{C} 1$. It can be seen that both the PI and EB methods can follow the reference well. However, the EB method has a stronger tracking capability with a smaller ripple. In particular, there is some tracking error for the PI method when the reference abruptly varies, which is shown in the detailed figure. However, the EB method avoids this problem. Besides, the PI method needs a disturbance recovery process whereas the EB method tracks very fast. Consequently, the anti-disturbance and tracking ability of the EB method are preferable to those of the PI method. 


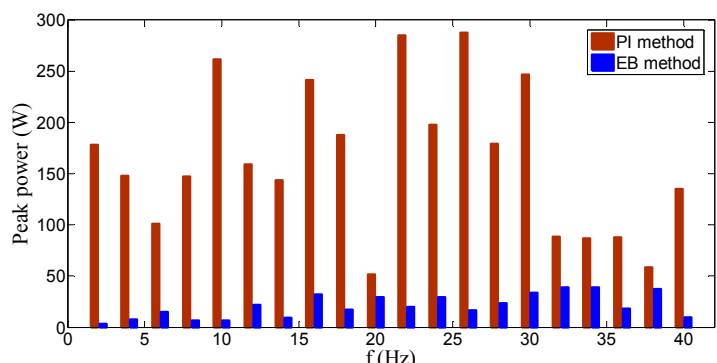

(a)

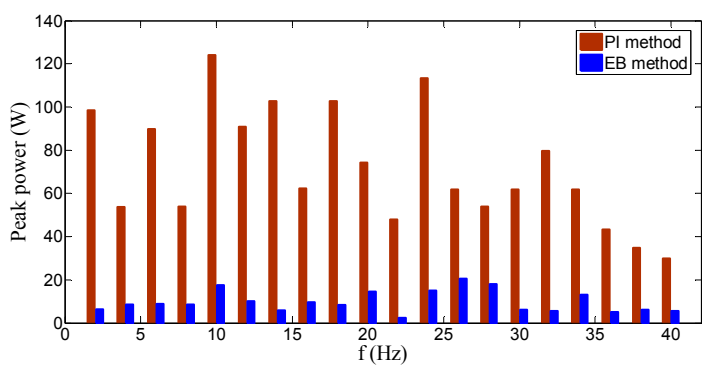

(b)

Figure 10. Comparison of low-frequency ripple. (a) Case C1; and (b) Case C2.

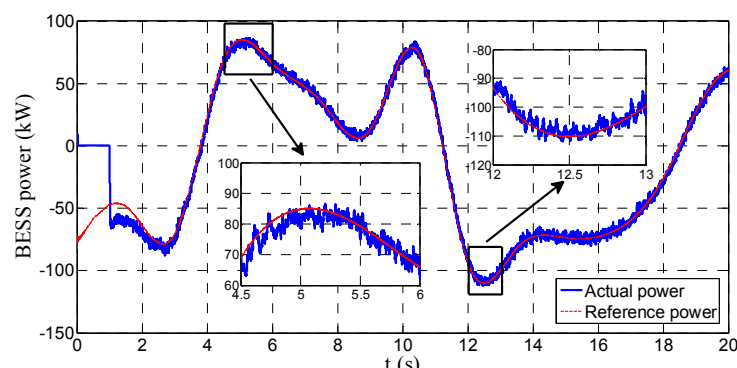

(a)

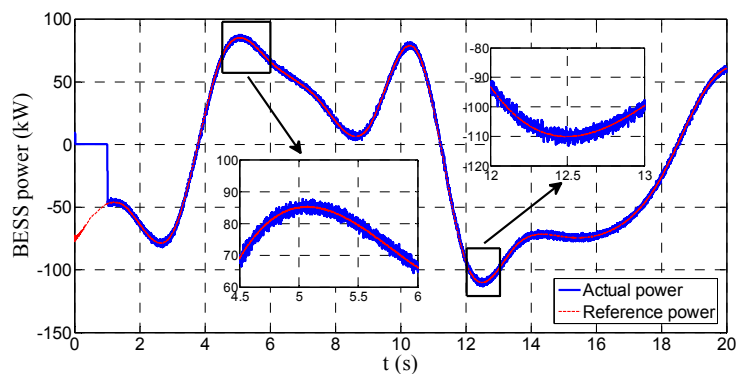

(b)

Figure 11. Performance of power tracking (case C1). (a) PI method; and (b) EB method.

\subsection{Islanded Mode Test}

BESSs are utilized to regulate the frequency and voltage in the islanded mode. The real power and reactive power references of a BESS are generated by extra $f-p$ and $v-q$ PI controllers, respectively. In this scenario, we assume the wind generation is constant at $P_{\mathrm{W}}=300 \mathrm{~kW}$ and the initial load is $P_{\mathrm{L}}=500 \mathrm{~kW}$. At $5 \mathrm{~s}$ the MG goes into islanded mode; at $10 \mathrm{~s}$ a $\Delta P_{\mathrm{L}}=40 \mathrm{~kW}$ resistor is connected to the MG, and it is disconnected at $15 \mathrm{~s}$. Figure 12 provides the power of some principle components of the MG in the islanded mode test.

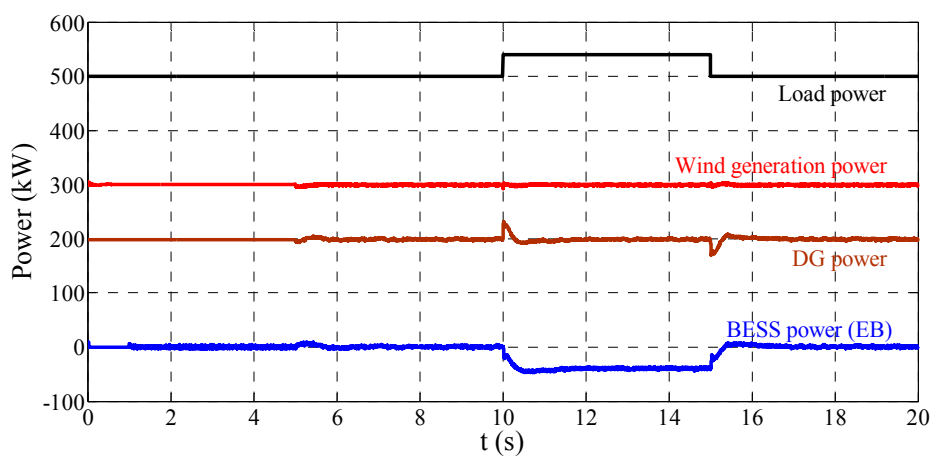

Figure 12. The power of some main parts of MG (islanded mode).

Figure 13a compares the frequency regulation performance between the PI and EB methods, and Figure $13 \mathrm{~b}$ demonstrates the contrast on voltage regulation. The performance of the PI and EB controllers is quite similar because the control performance mainly depends on the external $f-p$ and $v-q$ PI controllers and their outer PI controllers are the same. However, it can be found that the EB controller has a better transient performance and a lower ripple compared with the PI method. 


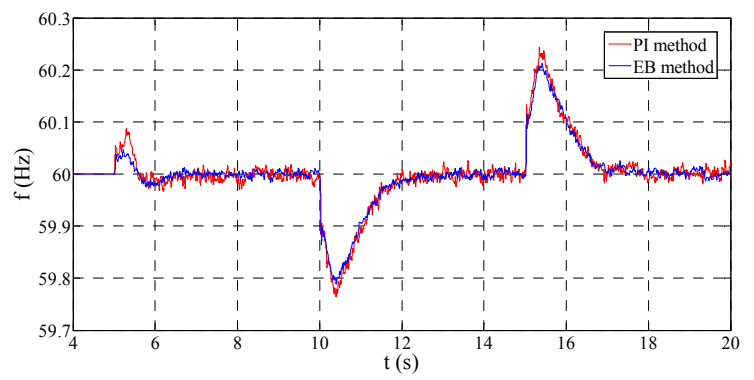

(a)

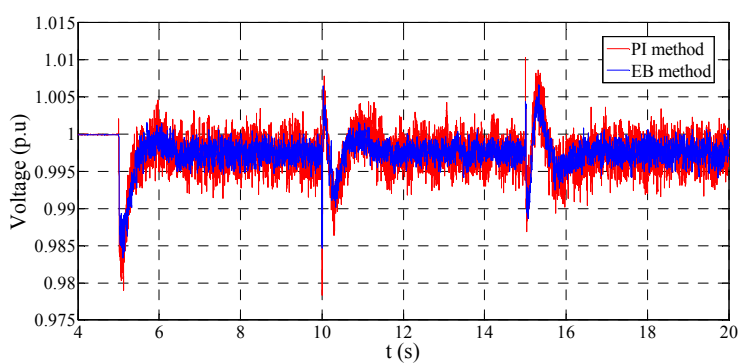

(b)

Figure 13. Performance in the islanded mode. (a) Frequency regulation; and (b) voltage regulation.

\subsection{Sensibility Analysis}

To analyze the influence of system parameters on the control performance, we implement a sensibility test for the designed controllers. Both of the grid-connected mode and islanded mode are considered. To evaluate the sensitivity levels of the system to parameter variations, we define the sensitivity analysis factor (SAF) [31] as:

$$
S A F=\frac{\Delta A / A}{\Delta F / F}
$$

In Equation (28), $\Delta A / A$ is the variation ratio of evaluation index; $\Delta F / F$ represents the change rate of the uncertainties. When $S A F>0$, it means that the evaluation index and uncertainty factors change in the same direction; when $S A F<0$, they are indicated to vary reversely. The larger $|S A F|$ is, the evaluation index $A$ is more sensitive to the uncertainty $F$. The change extent of $F$ is not important, and we are mainly concern about the $S A F$ to the parameter change.

In the grid-connected mode, we select the peak-ripple factor $(P R F)$ of the smoothed power as the evaluation index, for it can indicate not only the smoothness degree, but also the ripple level. We define the PRF as:

$$
P R F=\frac{P_{\mathrm{p}-\mathrm{p}}}{P_{\mathrm{dc}}}
$$

In Equation (29), $P_{\mathrm{p}-\mathrm{p}}$ is the peak-to-peak value of the smoothed power; $P_{\mathrm{dc}}$ is the average value of the smoothed power. The lower $P R F$ is, the smoother power and smaller ripples are achieved. The actual conditions should determine the tolerance level of $P R F$. We choose the tolerance margin of $P R F$ to be $8 \%$ in this study which corresponds to a maximum ripple peak-to-peak power of $24 \mathrm{~kW}$. We change several critical system parameters and test the $S A F$ performance in EB control system. The test results are shown in Table 2.

From Table 2, we can find the PRF performance is not sensitive to the variation of $R_{\mathrm{b}}, C$, $R_{\mathrm{g}}, \Delta P_{\mathrm{W}}$ and $P_{\mathrm{L}}$. It is moderately sensitive to the battery nominal voltage $E_{\mathrm{n}}$ because the control performance has a relationship with the DC voltage. Nevertheless, when $E_{\mathrm{n}}$ increases by $10 \%$ and reaches $880 \mathrm{~V}$ which is a very high value for the real system, the PRF value is still very low. The most sensitive factor is the $L_{\mathrm{g}}$ in the grid-connected mode. Figure 14 compares the steady-state $P R F$ performance between PI and EB methods when $L_{g}$ changes. It is worthy to note that the disturbance recovery process of PI method is excluded from the test range. To meet the demand of $P R F<8 \%$, we should choose $L_{\mathrm{g}}>0.33 \mathrm{mH}$ for the EB controller and $L_{\mathrm{g}}>0.71 \mathrm{mH}$ for the PI controller. 
Table 2. The sensitivity analysis factor ( $S A F)$ performance of energy-based (EB) control in the grid-connected mode.

\begin{tabular}{cccccc}
\hline Parameters & Change Rate (\%) & $\boldsymbol{P}_{\mathbf{d c}}(\mathbf{k W})$ & $\boldsymbol{P}_{\mathbf{p}-\mathbf{p}}(\mathbf{k W})$ & $\boldsymbol{P R F}(\%)$ & $\boldsymbol{S A F}$ \\
\hline No & 0 & 300 & 10.689 & 3.563 & $/$ \\
$E_{\mathrm{n}}$ & 10 & 300 & 11.25 & 3.75 & 0.5248 \\
$R_{\mathrm{b}}$ & 100 & 299.2 & 11.035 & 3.689 & 0.035 \\
$C$ & 10 & 300 & 10.591 & 3.53 & -0.0926 \\
$L_{\mathrm{g}}$ & -50 & 300 & 19.493 & 6.498 & -1.6473 \\
$R_{\mathrm{g}}$ & 100 & 300 & 11.215 & 3.738 & 0.049 \\
$\Delta P_{\mathrm{W}}{ }$ & 100 & 300.1 & 12.8 & 4.265 & 0.197 \\
$P_{\mathrm{L}}$ & 100 & 300 & 10.565 & 3.52 & -0.012 \\
\hline
\end{tabular}

${ }^{1} \Delta P_{\mathrm{W}}$ means the fluctuation of the wind generation.

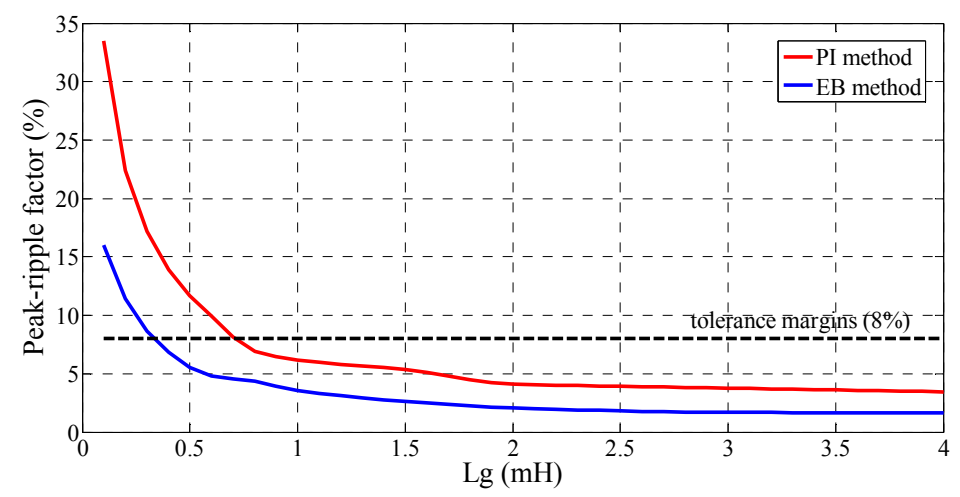

Figure 14. Steady-state peak-ripple factor $(P R F)$ performance of PI and EB methods when $L_{\mathrm{g}}$ changes.

In the islanded mode, we select the frequency overshoot value $\Delta f$ during the mode transition period (from $5 \mathrm{~s}$ to $6 \mathrm{~s}$ ) as the evaluation index. $\Delta f$ is defined as the difference between the peak frequency and the fixed frequency. The tolerance margin is determined as $\pm 0.5 \mathrm{~Hz}$ in this study. The SAF performance to the parameter variety in EB control system is provided in Table 3 . We can find the most sensitive parameters are the initial load power $P_{\mathrm{L}}$ and the wind generation power $P_{\mathrm{W}}$. Figure 15 demonstrates the frequency overshoot when these two parameters vary. To ensure the overshoot within the tolerance region, we can change the load power from $-14.54 \%$ to $18.68 \%$ for the PI control method. Whereas in EB control system the load variation region can be from $-15.82 \%$ to $20.6 \%$. The wind generation power can change from $-33.2 \%$ to $25.27 \%$ for the PI method. Whereas it can vary from $-37.3 \%$ to $29 \%$ in EB control system. The permitted change area of EB method is larger than that of the PI method.

Table 3. The $S A F$ performance of EB control in the islanded mode.

\begin{tabular}{cccc}
\hline Parameters & Change Rate $(\%)$ & $\Delta f(\mathbf{H z})$ & $S A F$ \\
\hline No & 0 & 0.0461 & $/$ \\
$E_{\mathrm{n}}$ & 10 & 0.0367 & -2.039 \\
$R_{\mathrm{b}}$ & 100 & 0.0388 & -0.158 \\
$C$ & 10 & 0.0414 & -1.0195 \\
$L_{\mathrm{g}}$ & 100 & 0.0384 & -0.167 \\
$R_{\mathrm{g}}$ & 100 & 0.0404 & -0.1236 \\
$P_{\mathrm{W}}$ & 10 & 0.1939 & 32.06 \\
$P_{\mathrm{L}}$ & -10 & 0.3152 & -58.37 \\
\hline
\end{tabular}




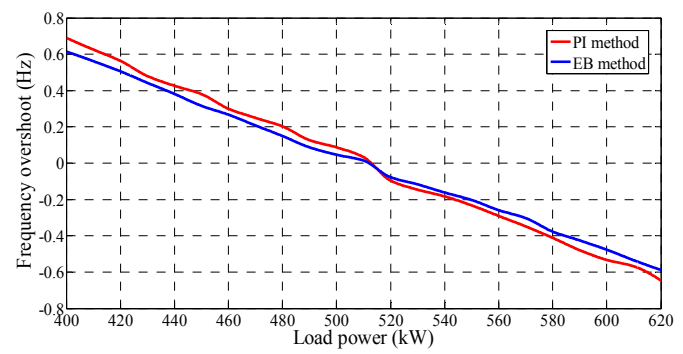

(a)

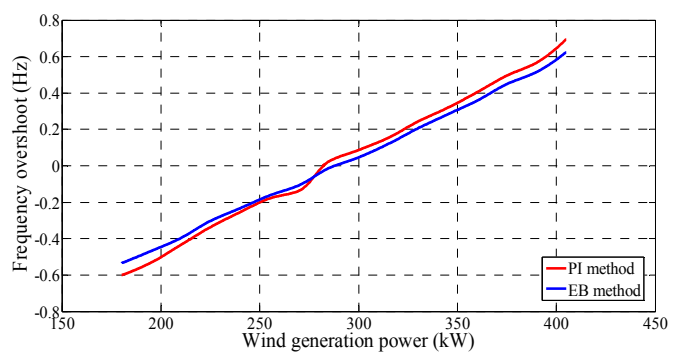

(b)

Figure 15. Frequency overshoot performance of PI and EB methods (at $5 \mathrm{~s}$ ). (a) When load power changes; and (b) when wind generation power changes.

\section{Conclusions}

In this study, EB method is applied in BESS to overcome the inherent drawbacks of the PI method and improve the control performance. Detailed step-by-step design method based on IDA strategy has been presented. Firstly, we have constructed the PCH model of BESS. Then the equilibrium point of control variable was solved. Afterward, the undetermined matrix was calculated and acquired. Finally, integral action has been combined to enhance the robustness of the EB method.

Case simulation results have demonstrated that the EB method has better performance both in the steady and transient state than PI method. Specifically, EB method has three advantages compared with the traditional PI method. Firstly, EB method has better tracking ability than PI method. EB method has a superior steady-state performance and a smaller ripple for the smoothed power. Secondly, EB method has better anti-disturbance capability than PI method. In the simulation, the PI method has a slow disturbance recovery process with a significant overshoot. Conversely, EB method only has a slight overshoot and nearly avoids the disturbance recovery process. Finally, EB method has the superior robustness to parameter uncertainty. The performance of the PI method is affected by parameters substantially, whereas EB method maintains a satisfactory performance.

Although the performance of EB control is better than PI control, the main drawback of EB control method is the higher design complexity, which limits the application of EB control in the power converters. However, the implementation of the EB control method is straightforward. The step-by-step designing process of EB control proposed in this study would be useful for the person who wants to study the EB control. The proposed EB control for the BESS does not depend on the MG configuration. The proposed method could be easily applied to the other MG configurations.

Acknowledgments: This research was supported by Post-Doctor Research Program (2016) through Incheon National University (INU), Incheon, Korea.

Author Contributions: The paper was a collaborative effort between the authors. The authors contributed collectively to the theoretical analysis, modeling, simulation, and manuscript preparation.

Conflicts of Interest: The authors declare no conflict of interest.

\section{Nomenclature}

\section{Abbreviations}

$\begin{array}{ll}\text { BESS } & \text { Battery energy storage system } \\ \text { EB } & \text { Energy-based } \\ \text { DG } & \text { Diesel generator } \\ \text { PCH } & \text { Port-controlled Hamiltonian } \\ \text { IDA } & \text { Interconnection and damping assignment } \\ \text { SOC } & \text { State of charge } \\ \text { SAF } & \text { Sensitivity analysis factor } \\ \text { PRF } & \text { Peak-ripple factor } \\ \text { MG } & \text { Microgrid }\end{array}$


Variables, Parameters, and Constants

\begin{tabular}{|c|c|}
\hline$P_{\mathrm{W}}, P_{\mathrm{G}}, P_{\mathrm{D}}, P_{\mathrm{L}}$ & The power of wind generation/utility grid/DG/load \\
\hline$P_{\mathrm{B}}, P_{\mathrm{B}}^{*}$ & BESS input actual/reference power \\
\hline$P_{\mathrm{E}}, P_{\mathrm{A}}$ & Expected/actual wind generation output power \\
\hline$E_{\mathrm{g}}, E_{\mathrm{n}}, R_{\mathrm{b}}$ & Controlled voltage source/Nominal voltage/Internal resistance of the battery \\
\hline C & The DC capacitance of VSC \\
\hline$L_{\mathrm{g}}$ & The inductance of the connection inductor \\
\hline$R_{\mathrm{g}}$ & The total internal resistance of connection inductor and IGBTs \\
\hline$T_{\mathrm{S}}$ & The sampling period of the system \\
\hline$P^{*}, Q^{*}$ & The real/reactive power reference of BESS \\
\hline$P_{\mathrm{g}}^{*}, Q_{\mathrm{g}}^{*}$ & The real/reactive power reference of BESS in grid-connected mode \\
\hline$P_{i}^{*}, Q_{i}^{*}$ & The real/reactive power reference of BESS in islanded mode \\
\hline$i_{\mathrm{gd}}, i_{\mathrm{gq}}$ & BESS current in $\mathrm{d} / \mathrm{q}$ axis \\
\hline$i_{\mathrm{gd}}^{*} i_{\mathrm{gq}}^{*}$ & BESS current reference in $d / q$ axis \\
\hline$u_{\mathrm{gd}}, u_{\mathrm{gq}}$ & Grid voltage in $\mathrm{d} / \mathrm{q}$ axis \\
\hline$s_{\mathrm{d}}, s_{\mathrm{q}}$ & The duty cycle in $\mathrm{d} / \mathrm{q}$ axis \\
\hline$\omega_{0}$ & Fundamental angle frequency \\
\hline$u_{\mathrm{dc}}$ & The DC voltage of VSC \\
\hline$f, v$ & Frequency/voltage \\
\hline$f^{*}, v^{*}$ & Frequency/voltage reference \\
\hline$p, q$ & Real/reactive power \\
\hline$k_{\mathrm{p}}, k_{\mathrm{i}}$ & The proportional/integral coefficient in PI current controller \\
\hline$k_{\mathrm{pf}}, k_{\mathrm{if}}$ & The proportional/integral coefficient in external $f-p$ controller \\
\hline$k_{\mathrm{pv}}, k_{\mathrm{iv}}$ & The proportional/integral coefficient in external $v-q$ controller \\
\hline$K_{\mathrm{I}}$ & The integral coefficient in EB controller \\
\hline$u, y$ & The conjugate input and port output variable in $\mathrm{PCH}$ model \\
\hline$J(x), g(x)$ & The internal structure matrices in $\mathrm{PCH}$ model \\
\hline$J_{\mathrm{d}}(x), R_{\mathrm{d}}(x)$ & Desired interconnection/damping matrix in $\mathrm{PCH}$ model \\
\hline$H(x), H_{\mathrm{d}}(x)$ & The original/desired Hamilton energy function in $\mathrm{PCH}$ model \\
\hline$J_{\mathrm{a}}(x), R_{\mathrm{a}}(x)$ & The interconnection/damping matrix awaiting to be determined \\
\hline$H_{\mathrm{a}}(x)$ & Hamilton energy function awaiting to be determined in PCH model \\
\hline
\end{tabular}

\section{Appendix A}

Table A1. The comparison of the performance between PI and EB methods.

\begin{tabular}{ccccc}
\hline Performance Index & Working Mode & Parameters of $L_{\mathbf{g}}(\mathbf{m H}), \boldsymbol{R}_{\mathbf{g}}(\boldsymbol{\Omega})$ & PI Method & EB Method \\
\hline Starting overshoot & Step response & $1,1.1 \times 10^{-3}$ & $-21 \mathrm{~kW}$ & $11 \mathrm{~kW}$ \\
Starting overshoot & Step response & $4,0.2$ & $-36 \mathrm{~kW}$ & $2.6 \mathrm{~kW}$ \\
Starting regulation time & Step response & $1,1.1 \times 10^{-3}$ & $2.2 \mathrm{~s}$ & $0.03 \mathrm{~s}$ \\
Starting regulation time & Step response & $4,0.2$ & $4.3 \mathrm{~s}$ & $0.035 \mathrm{~s}$ \\
Starting overshoot & Grid-connected & $1,1.1 \times 10^{-3}$ & $20 \mathrm{~kW}$ & $1.9 \mathrm{~kW}$ \\
Starting overshoot & Grid-connected & $4,0.2$ & $35.5 \mathrm{~kW}$ & $2.4 \mathrm{~kW}$ \\
Starting regulation time & Grid-connected & $1,1.1 \times 10^{-3}$ & $2.7 \mathrm{~s}$ & $0.02 \mathrm{~s}$ \\
Starting regulation time & Grid-connected & $4,0.2$ & $4.6 \mathrm{~s}$ & $0.03 \mathrm{~s}$ \\
Average ripple RMS value & Grid-connected & $1,1.1 \times 10^{-3}$ & $2.5 \mathrm{~kW}$ & $1.05 \mathrm{~kW}$ \\
Average ripple RMS value & Grid-connected & $4,0.2$ & $1.6 \mathrm{~kW}$ & $0.6 \mathrm{~kW}$ \\
Steady-state PRF & Grid-connected & $1,1.1 \times 10^{-3}$ & $6.16 \%$ & $3.56 \%$ \\
Frequency overshoot $(5 \mathrm{~s})$ & Islanded & $1,1.1 \times 10^{-3}$ & $0.087 \mathrm{~Hz}$ & $0.046 \mathrm{~Hz}$ \\
Frequency overshoot $(10 \mathrm{~s})$ & Islanded & $1,1.1 \times 10^{-3}$ & $-0.236 \mathrm{~Hz}$ & $-0.211 \mathrm{~Hz}$ \\
Frequency overshoot $(15 \mathrm{~s})$ & Islanded & $1,1.1 \times 10^{-3}$ & $0.244 \mathrm{~Hz}$ & $0.212 \mathrm{~Hz}$ \\
\hline
\end{tabular}




\section{References}

1. Guo, L.; Liu, W.; Li, X.; Liu, Y.; Jiao, B.; Wang, W.; Wang, C.; Li, F. Energy management system for stand-alone wind-powered-desalination microgrid. IEEE Trans. Smart Grid 2016, 7, 1079-1087. [CrossRef]

2. Xu, X.; Bishop, M.; Oikarinen, D.G.; Hao, C. Application and modeling of battery energy storage in power systems. CSEE J. Power Energy Syst. 2016, 2, 82-90. [CrossRef]

3. Lan, Y.; Guan, X.; Wu, J. Rollout strategies for real-time multi-energy scheduling in microgrid with storage system. IET Gener. Transm. Distrib. 2016, 10, 688-696. [CrossRef]

4. Tang, X.; Hu, X.; Li, N.; Deng, W.; Zhang, G. A novel frequency and voltage control method for islanded microgrid based on multienergy storages. IEEE Trans. Smart Grid 2016, 7, 410-419. [CrossRef]

5. Guo, W.; Xiao, L.; Dai, S. Fault current limiter-battery energy storage system for the doubly-fed induction generator: Analysis and experimental verification. IET Gener. Transm. Distrib. 2016, 10, 653-660. [CrossRef]

6. Arunprasanth, S.; Annakkage, U.D.; Karawita, C.; Kuffel, R. Generalized frequency-domain controller tuning procedure for VSC systems. IEEE Trans. Power Deliv. 2016, 31, 732-742. [CrossRef]

7. Khorramabadi, S.S.; Bakhshai, A. Critic-based self-tuning PI structure for active and reactive power control of VSCs in microgrid systems. IEEE Trans. Smart Grid 2015, 6, 92-103. [CrossRef]

8. Freijedo, F.D.; Vidal, A.; Yepes, A.G.; Guerrero, J.M.; López, Ó.; Malvar, J.; Doval-Gandoy, J. Tuning of synchronous-frame PI current controllers in grid-connected converters operating at a low sampling rate by MIMO root locus. IEEE Trans. Ind. Electron. 2015, 62, 5006-5017. [CrossRef]

9. Akter, M.P.; Mekhilef, S.; Tan, N.M.L.; Akagi, H. Modified model predictive control of a bidirectional AC-DC converter based on Lyapunov function for energy storage systems. IEEE Trans. Ind. Electron. 2016, 63, 704-715. [CrossRef]

10. Lee, T.-S. Lagrangian modeling and passivity-based control of three-phase AC/DC voltage-source converters. IEEE Trans. Ind. Electron. 2004, 51, 892-902. [CrossRef]

11. Song, E.; Lynch, A.F.; Dinavahi, V. Experimental validation of nonlinear control for a voltage source converter. IEEE Trans. Control Syst. Technol. 2009, 17, 1135-1144. [CrossRef]

12. Yi, H.; Zhuo, F.; Wang, F.; Wang, Z. A digital hysteresis current controller for three-level neural-point-clamped inverter with mixed-levels and prediction-based sampling. IEEE Trans. Power Electron. 2016, 31, 3945-3957. [CrossRef]

13. Flores-Bahamonde, F.; Valderrama-Blavi, H.; Bosque-Moncusi, J.M.; García, G.; Martínez-Salamero, L. Using the sliding-mode control approach for analysis and design of the boost inverter. IET Power Electron. 2016, 9, 1625-1634. [CrossRef]

14. Tanasa, V.; Monaco, S.; Normand-Cyrot, D. Backstepping control under multi-rate sampling. IEEE Trans. Autom. Control 2016, 61, 1208-1222. [CrossRef]

15. Sreeraj, E.S.; Prejith, E.K.; Chatterjee, K.; Bandyopadhyay, S. An active harmonic filter based on one-cycle control. IEEE Trans. Ind. Electron. 2014, 61, 3799-3809.

16. Tao, C.-W.; Wang, C.-M.; Chang, C.-W. A design of a DC-AC inverter using a modified ZVS-PWM auxiliary commutation pole and a DSP-based PID-like fuzzy control. IEEE Trans. Ind. Electron. 2016, 63, 397-405. [CrossRef]

17. Nageshrao, S.P.; Lopes, G.A.D.; Jeltsema, D.; Babuška, R. Port-Hamiltonian systems in adaptive and learning control: A survey. IEEE Trans. Autom. Control 2016, 61, 1223-1238. [CrossRef]

18. Schöberl, M.; Siuka, A. On Casimir functionals for infinite-dimensional port-Hamiltonian control systems. IEEE Trans. Autom. Control 2013, 58, 1823-1828. [CrossRef]

19. Dirksz, D.A.; Scherpen, J.M.A. Structure preserving adaptive control of port-Hamiltonian systems. IEEE Trans. Autom. Control 2012, 57, 2880-2885. [CrossRef]

20. Nunna, K.; Sassano, M.; Astolfi, A. Constructive interconnection and damping assignment for port-controlled Hamiltonian systems. IEEE Trans. Autom. Control 2015, 60, 2350-2361. [CrossRef]

21. Kwasinski, A.; Krein, P.T. Passivity-based control of buck converters with constant-power loads. In Proceedings of the 2007 IEEE Power Electronics Specialists Conference (PESC), Orlando, FL, USA, 17-21 June 2007; pp. 259-265.

22. Zeng, J.; Zhang, Z.; Qiao, W. An interconnection and damping assignment passivity-based controller for a DC-DC boost converter with a constant power load. IEEE Trans. Ind. Appl. 2014, 50, 2314-2322. [CrossRef] 
23. Qiu, J.; Hu, C.; Yang, S. PMSM Hamiltonian energy shaping control with parameters self-tuning PID control. In Proceedings of the 2015 34th Chinese Control Conference (CCC), Hangzhou, China, 28-30 July 2015; pp. 4506-4511.

24. Tang, Y.; Yu, H.; Zou, Z. Hamiltonian modeling and energy-shaping control of three-phase AC/DC voltage-source converters. In Proceedings of the 2008 IEEE International Conference on Automation and Logistics (ICAL), Qingdao, China, 1-3 September 2008; pp. 591-595.

25. Yu, H.; Teng, Z.; Yu, J.; Zang, Y. Energy-shaping and passivity-based control of three-phase PWM rectifiers. In Proceedings of the 2012 10th World Congress on Intelligent Control and Automation (WCICA), Beijing, China, 6-8 July 2012; pp. 2844-2848.

26. Serra, F.M.; Angelo, C.H.D.; Forchetti, D.G. IDA-PBC control of a three-phase front-end converter. In Proceedings of the 2012 38th Annual Conference on IEEE Industrial Electronics Society (IECON), Montreal, QC, Canada, 25-28 October 2012; pp. 5203-5208.

27. Liang, Z.; Xie, Z.; Wei, X.; Zhang, H. Computer control design of active power filter based on the energy shaping control principle. In Proceedings of the 2009 WRI World Congress on Computer Science and Information Engineering, Los Angeles, CA, USA, 31 March-2 April 2009; pp. 196-200.

28. Tremblay, O.; Dessaint, L.-A.; Dekkiche, A.-I. A generic battery model for the dynamic simulation of hybrid electric vehicles. In Proceedings of the 2007 IEEE Vehicle Power and Propulsion Conference (VPPC), Arlington, TX, USA, 9-12 September 2007; pp. 284-289.

29. Donaire, A.; Junco, S. On the addition of integral action to port-controlled Hamiltonian systems. Automatica 2009, 45, 1910-1916. [CrossRef]

30. Yazdani, A.; Iravani, R. Voltage-Sourced Converters in Power Systems: Modeling, Control, and Applications; John Wiley \& Sons: Somerset, NJ, USA, 2010; pp. 217-226.

31. Hamby, D.M. A review of techniques for parameter sensitivity analysis of environmental models. Environ. Monit. Assess. 1994, 32, 135-154. [CrossRef] [PubMed]

(C) 2017 by the authors; licensee MDPI, Basel, Switzerland. This article is an open access article distributed under the terms and conditions of the Creative Commons Attribution (CC BY) license (http:/ / creativecommons.org/licenses/by/4.0/). 